\title{
UTJECAJ RAZLIČITIH VRSTA PODLOGA I RADNIH SATI TRAKTORA NA PROIZVEDENU RAZINU BUKE
}

\author{
IMPACT OF DIFFERENT TYPES OF SURFACES AND TRACTOR \\ OPERATING HOURS ON PRODUCED NOISE LEVEL
}

\author{
Ž. Barač, I. Plaščak, M. Jurišić, D. Zimmer
}

\section{SAŽETAK}

U radu su prikazani rezultati mjerenja buke traktora LANDINI POWERFARM DT100A. Mjerenje buke obavljeno je na tri različite podloge (makadam, asfalt i trava) tijekom 2015. i 2016. godine. Mjerenje je obavljeno uređajem proizvođača METREL tipa Multinorm MI 620I EU, prema normi HRN ISO 6396 koja se odnosi na mjerenje buke s lijeve i desne strane rukovatelja, pri čemu se traktor gibao oko $7,5 \mathrm{~km} / \mathrm{h}$, te prema normi HRN ISO 5131, koja propisuje točni položaj uređaja u odnosu na referentnu točku sjedala rukovatelja. Iz rezultata je vidljivo da ispitivani traktor najvišu razinu buke proizvodi na makadamskoj podlozi, dok najmanju razinu buke proizvodi na travnatoj podlozi. Razina buke koju proizvodi ispitivani traktor manja je od $90 \mathrm{~dB}$.

Ključne riječi: podloge, buka, poljoprivredni traktor

\section{ABSTRACT}

This paper presents the results of the LANDINI POWERFARM DT100A tractor noise measurement. Noise measurements were made while tractor was moving on three different surfaces (macadam, asphalt and grass) during 2015 and 2016. The measurement was carried out by the device METREL manufacturer type Multinorm MI 620I EU. The same was done according to HRN ISO 6396, which refers to noise measurement on the left and right of the operator, with the tractor moving about $7.5 \mathrm{~km} / \mathrm{h}$ and according to HRN ISO 5131, which prescribes the exact position of the device in relation to the reference point at the operator's seat. The results show that the tested tractor produces the highest noise level on the macadam, while the lowest noise level is produced on a grassy surface. The noise level produced by the tested tractor is less than $90 \mathrm{~dB}$.

Keywords: surface, noise, agricultural tractor 


\section{UVOD}

Izvori zvuka su tijela koja titraju frekvencijom od 16 do $20000 \mathrm{~Hz}$ u nekom elastičnom sredstvu, npr. napeta struna ili glazbena vilica $u$ zraku. Najjednostavniji oblik titranja izvora zvuka je harmoničko titranje. Harmoničko titranje stvara harmoničke valove. Čisti ton nastaje ako se frekvencija titranja ne mijenja. Složeni tonovi sadrže više frekvencija. Šum je posljedica potpuno nepravilnog titranja. Valovi nastali titranjem izvora frekvencijom većom od $20 \mathrm{kHz}$ opisuju se kao ultrazvuk (mogu ih čuti neke životinje, npr. psi i šišmiši), a frekvencijom manjom od $16 \mathrm{~Hz}$ kao infrazvuk (mogu ih čuti npr. patke i slonovi) (URL 1).

Isti autori navode da brzina zvučnih valova ovisi o sredstvu kroz koje se ti valovi šire. Tako je brzina zvuka u zraku $331 \mathrm{~m} / \mathrm{s}$, u vodi $1485 \mathrm{~m} / \mathrm{s}$, a u staklu $5500 \mathrm{~m} / \mathrm{s}$. Ako se izvor ili prijamnik zvučnih valova gibaju u odnosu na sredstvo kroz koje se valovi šire, prijamnik bilježi promjenu frekvencije tzv. dopplerov efekt. Pojava kada ljudsko uho osjeća zvukom izazvanu promjenu tlaka zraka naziva se akustički tlak. Za zvučni val frekvencije $1 \mathrm{kHz}$ i jakosti koja odgovara pragu čujnosti $\left(\mathrm{I} O=10-12 \mathrm{~W} / \mathrm{m}^{2}\right)$, amplituda pomaka čestice iznosi oko $10-11 \mathrm{~m}$, dok je amplituda akustičkoga tlaka oko $2 \cdot 10^{-5} \mathrm{~Pa}$. Za zvuk na granici bola pomak je čestice $10-5 \mathrm{~m}$, a akustički tlak $30 \mathrm{~Pa}$.

Zvučni val se širi na dva načina. U zraku, plinovima i vodi zvučni se val širi isključivo kao longitudinalni val, jer prijenos čestice sredstva titraju u smjeru širenja vala. U čvrstim tvarima širi se kao transverzalni val, jer čestice materije titraju okomito na smjer širenja vala. (URL 2). Isti autori navode kako širenje zvuka u prostorijama drukčije je od širenja zvuka u otvorenom prostoru. U otvorenom prostoru, u idealnim uvjetima, zvučni valovi ne nailaze na prepreke.

Uho se sastoji od tri područja: vanjskog, srednjeg i unutarnjeg uha. Vanjsko uho prihvaća zvuk, komprimira ga i prenosi na bubnjić koji počinje vibrirati. Srednje uho pojačava ove vibracije zvuka i usmjerava ih na unutarnje uho, gdje se one pretvaraju u električne impulse. Kroz slušni živac impuls dolazi u mozak - čujemo šum, ton, zvuk ili prasak (URL 4).

Buka je subjektivni pojam, određen fizikalnim značajkama zvuka i fiziološkim svojstvima uha i ljudskog organizma. Buka je zvučna akustična energija koja može štetno djelovati na fiziološko i psihološko stanje ljudi. Bukom se naziva svaki neželjeni i neugodni zvuk, odnosno smjesa zvukova različitih svojstava, koja može biti trajna, isprekidana i udarna, promjenljive 
razine, različitog trajanja i vremenske raspodjele (URL 3). Isti autori navode da je buka važan javnozdravstveni i ekološki problem jer prema brojnim istraživanjima, zagađenja bukom iz vanjskog i unutarnjeg okoliša utječu i još više će utjecati na ljudsko zdravlje.

Prema podacima Hrvatskog zavoda za zdravstveno osiguranje (URL 5), najčešće dijagnosticirane profesionalne bolesti u Republici Hrvatskoj su bolesti izazvane štetnim djelovanjem vibracija, te oštećenja sluha uzrokovana djelovanjem buke. Kako se ovi službeni podaci odnose ne samo na zaposlene radnike, nego i na radnike u poljoprivredi, za pretpostaviti je da se i kod članova poljoprivrednih gospodarstava pojavljuju navedene bolesti. Prekomjerna buka može uzrokovati oštećenja i gubitak sluha rukovatelja poljoprivrednog traktora. Danas se zaštita rukovatelja od negativnog utjecaja buke uspješno provodi osobnim zaštitnim sredstvima u obliku raznih čepića ili štitnika koji su vrlo lagani i ugodni za nošenje (Fabijanić, 2010.).

Najveća dopuštena razina buke unutar kabine poljoprivrednog traktora je $90 \mathrm{~dB}$ pri mjerenju u skladu s Prilogom I (NN 79/10.).

Mjerenjem buke pri četiri vrste opterećenja u kabini traktora JOHN DEERE 8520 dobivene razine buke bile su ispod dopuštenih granica kako su utvrdili Goglia i sur. (2005.). Isti autori navode da izmjerena razina buke omogućava rukovatelju stroja ugodan rad kroz puno radno vrijeme bez pojave zamora. Goglia i sur. (2007.) mjerenjem razine buke u kabini traktora proizvođača IMT 549 utvrđuju da ona iznosi $81 \mathrm{~dB}$. Razina mjerene buke ne prelazi vrijednost najviše dnevne ili tjedne razine od dozvoljenih $90 \mathrm{~dB}$ te nema opasnosti za oštećenje sluha rukovatelja. Prema Savinu i sur. (2006.) izmjerena razina buke na traktoru proizvođača FENDT $930 \mathrm{u}$ kabini rukovatelja pri punom opterećenju tijekom oranja iznosi 77,5 dB. Osim unutarnje mjerena je i vanjska buka na razmaku od 7,5 $\mathrm{m}$ od uzdužne osi traktora na visini $1 \mathrm{~m}$ gdje je manja razina buke izmjerena $\mathrm{s}$ lijeve strane traktora $(82,0 \mathrm{~dB})$, dok je veća razina buke izmjerena s desne strane traktora $(88,9 \mathrm{~dB})$. Mjerenjem vanjske i unutarnje buke kod traktora YTO 454 razina izmjerene vanjske buke sa strane ispušnog lonca iznosila je $85,3 \mathrm{~dB}$, dok je sa suprotne strane iznosila $84,2 \mathrm{~dB}$. Izmjerena unutarnja razina buke pri zatvorenim vratima i prozorima iznosi $88,1 \mathrm{~dB}$, a pri otvorenim vratima i prozorima $89,2 \mathrm{~dB}$ (Savin i sur., 2011.). Barač i sur. (2015.) navode da razina mjerene buke na ispitivanim traktorima FENDT 410 ne prelazi 90 dB. Celen i Ann (2003.) navode da buka na traktoru NEW HOLLAND L 95 iznosi $81,6 \mathrm{~dB}$ na prednjem dijelu, a $80,6 \mathrm{~dB}$ na stražnjem dijelu traktora. Barač 
i sur. (2016.) pri mjerenju razine buke na traktoru LANDINI POWERFARM DT100A utvrđuju da niti jedna izmjerena vrijednost ne prelazi dopuštenu granicu od $90 \mathrm{~dB}$. Monazzan i sur. (2012.), istražujući razinu buke na rumunjskom traktoru M-650, utvrđuju najveću razinu buke pri 1700 okretaja motora. Isti autori navode da na lijevoj strani buka iznosi 91,6 dB, dok na desnoj strani iznosi 98,6 dB. Nadalje, autori navode da ovaj traktor pri 850 okretaja motora, proizvodi razinu buke od $87,2 \mathrm{~dB}$ na lijevoj strani te $85,9 \mathrm{~dB}$ na desnoj strani.

\section{CILJ ISTRAŽIVANJA}

Cilj istraživanja je utvrditi proizvedenu razinu buke pri različitim vrstama podloga u odnosu na radne sate traktora, te postoji li veza između pojedine podloge i proizvedene razine buke. Hipoteza je da će se povećanjem broja radnih sati poljoprivrednog traktora proizvedena razina buke povećati.

\section{MATERIJAL I METODE}

Istraživanje je obavljeno 2015. i 2016. godine na traktoru LANDINI POWERFARM DT100A. Mjerenje razine buke obavljeno je prema normi HRN ISO 6396 koja se odnosi na buku unutar kabine traktora, na proizvodnim površinama i pristupnim cestama srednje Poljoprivredne i veterinarske škole u Osijeku. Prilikom istraživanja 2015. i 2016. godine temperatura zraka iznosila je od $29{ }^{\circ} \mathrm{C}$ do $31{ }^{\circ} \mathrm{C}$, relativna vlažnost zraka iznosila je od $62 \%$ do $64 \%$, a brzina vjetra bila je zanemariva. Traktor je prilikom istraživanja 2015. godine imao 5800 radnih sati, a prilikom mjerenja 2016. godine imao je oko 6800 radnih sati. Mjerenje buke obavljeno je uređajem proizvođača METREL tipa Multinorm MI 6201 EU s pripadajućom zvučnom sondom (mikrofonom klase B) istog proizvođača.

Prema HRN ISO 6396 obavljeno je mjerenje s lijeve i desne strane rukovatelja dok se traktor gibao pri prosječnoj brzini oko 7,5 km h-1. Prema normi HRN ISO 5131 određeno je da se uređaj mora nalaziti, u odnosu na referentnu točku sjedala rukovatelja, od sredine glave rukovatelja do razine sjedala na visini od $790 \pm 20 \mathrm{~mm}$ i odmaknuto od sredine glave $200 \pm 20 \mathrm{~mm} \mathrm{~s}$ lijeve i desne strane. 
Obrađivani podaci označeni su s LAeq, što predstavlja vremenski usrednjeno ili ekvivalentno trajanje zvučne razine koja se mjeri u oba mjerna kanala.

Izmjerene vrijednosti statistički su obrađene primjenom dodatka za statističku obradu podataka programskog paketa MS Office Excel 2013 i programom IBM SPSS Statistics v.19.0.1. U radu su prikazane deskriptive statističke vrijednosti te analiza varijance.

\section{REZULTATI I RASPRAVA}

Usporedni prikaz razine buke na makadamskoj, asfaltnoj i travnatoj podlozi prikazuje dijagram broj 1 .

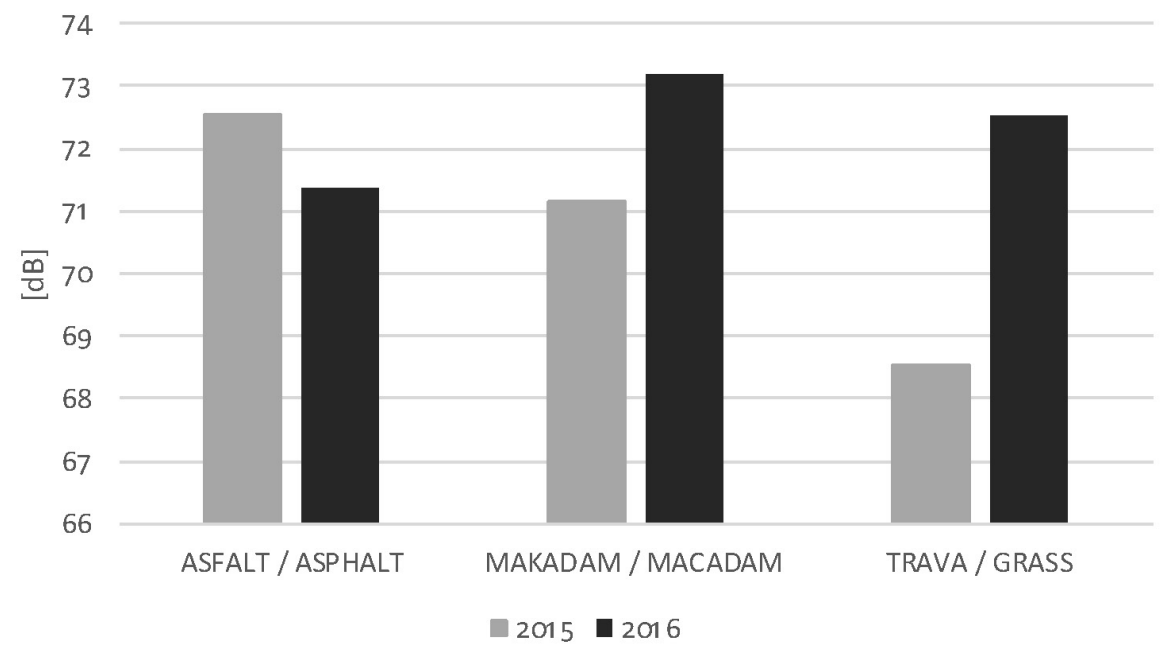

Dijagram 1. Usporedni prikaz srednjih vrijednosti buke na različitim podlogama 2015. i 2016. godine

Figure 1. A comparison of mean noise values on different surfaces in 2015 and 2016

Na dijagramu 1. vidljivo je da je najviša vrijednost ekvivalentne usrednjene trajne zvučne razine buke (LAeq) izračunata na makadamskoj podlozi u drugoj godini (2016.) istraživanja gdje je iznosila 73,2 dB, dok je najmanji iznos buke izmjeren na travnatoj podlozi u prvoj godini (2015.) istraživanja i iznosio je 68,55 dB. Traktor LANDINI POWERFARM DT100A prilikom mjerenja nije 
proizvodio buku veću od $90 \mathrm{~dB}$, što se podudara s istraživanjima Goglia i sur. (2007.) i Savina i sur. (2006.). Budući da je izmjerena razina buke bila manja od $90 \mathrm{~dB}$ rukovatelj nije morao koristiti zaštitna sredstava za zaštitu od buke.

\section{USPOREDNI STATISTIČKI PRIKAZ IZMJERENE BUKE}

\section{I 2016. GODINE}

Standardna pogreška veća je prilikom mjerenja 2016. godine (2) kod agrotehničkih podloga asfalt $(0,6173)$ i trava $(0,6351)$, dok je na makadamskoj podlozi standardna pogreška veća 2015 godine (1) iznosa 0,7810 (tablica 1).

Tablica 1. Deskriptivna statistika srednjih vrijednosti s desne strane pri gibanju na različitim podlogama (2015. i 2016. godina)

Table 1 Descriptive statistics of the mean values of the right side when moving on different surfaces (2015 and 2016)

\begin{tabular}{|c|c|c|c|c|c|c|c|c|c|}
\hline \multirow{2}{*}{ Grupa } & \multirow{2}{*}{$\mathrm{N}$} & \multirow{2}{*}{$\begin{array}{c}\bar{x} \\
\mathrm{LA}_{\mathrm{eq}}, \mathrm{dB} \\
\text { Mean } L A_{\text {eq }}\end{array}$} & \multirow{2}{*}{$\sigma$} & \multirow{2}{*}{$\begin{array}{l}\mathrm{K} . \mathrm{V} . \\
\% \\
\text { C. } V .\end{array}$} & \multirow{2}{*}{$\begin{array}{l}\text { Std. } \\
\text { Pogreška } \\
\text { Std. } \\
\text { Error }\end{array}$} & \multicolumn{2}{|c|}{$\begin{array}{l}\text { 95\% Interval pouzdanosti } \\
\text { za srednju vrijednost } \\
\text { 95\% Confidence Interval } \\
\text { for Mean }\end{array}$} & \multirow{2}{*}{ Min } & \multirow{2}{*}{ Max } \\
\hline & & & & & & $\begin{array}{l}\text { Niža } \\
\text { granica } \\
\text { Lower } \\
\text { bound }\end{array}$ & $\begin{array}{l}\text { Niža } \\
\text { granica } \\
\text { Lower } \\
\text { bound }\end{array}$ & & \\
\hline \multicolumn{10}{|c|}{ ASFALT / ASPHALT } \\
\hline 1 & 3 & 70,36 & 0,45 & 0,6408 & 0,2603 & 69,247 & 71,487 & 69,9 & 70,8 \\
\hline 2 & 3 & 71,33 & 1,06 & 1,4990 & 0,6173 & 68,677 & 73,990 & 70,1 & 72,0 \\
\hline Total & 6 & 70,85 & 0,90 & 1,2773 & 0,3695 & 69,900 & 71,800 & 69,9 & 72,0 \\
\hline \multicolumn{10}{|c|}{ MAKADAM / MACADAM } \\
\hline 1 & 3 & 72,60 & 1,35 & 1,8634 & 0,7810 & 69,247 & 71,487 & 69,9 & 70,8 \\
\hline 2 & 3 & 71,76 & 0,85 & 1,1851 & 0,4910 & 68,677 & 73,990 & 70,1 & 72,0 \\
\hline Total & 6 & 72,18 & 1,10 & 1,5362 & 0,4527 & 69,900 & 71,800 & 69,9 & 72,0 \\
\hline \multicolumn{10}{|c|}{ TRAVA / GRASS } \\
\hline 1 & 3 & 68,60 & 0,80 & 1,1661 & 0,4619 & 66,613 & 70,587 & 67,8 & 69,4 \\
\hline 2 & 3 & 71,80 & 1,10 & 1,5320 & 0,6351 & 69,067 & 74,533 & 70,7 & 72,9 \\
\hline Total & 6 & 70,20 & 1,95 & 2,7811 & 0,7971 & 68,151 & 72,249 & 67,8 & 72,9 \\
\hline
\end{tabular}


Iz tablice 2. vidljivo je da analizom varijance nije utvrđena statistički značajna razlika u iznosu srednjih vrijednosti izmjerene buke 2015. i 2016. godine na asfaltu i makadamu, dok je na travnatoj podlozi utvrđena statistički značajna razlika u iznosu srednjih vrijednosti izmjerene buke 2015. i 2016. godine.

Tablica 2. Analiza varijance (ANOVA) s desne strane pri gibanju na različitim podlogama (2015. i 2016. godina)

Table 2 Analysis of variance (ANOVA) of the right side when moving on different surfaces (2015 and 2016)

\begin{tabular}{|c|c|c|c|c|c|}
\hline & $\begin{array}{l}\text { Suma kvadrata } \\
\text { Sum of Squares }\end{array}$ & df & $\begin{array}{c}\text { Srednja vr. Kvadrata } \\
\text { Mean Square }\end{array}$ & $\mathrm{F}$ & Sig. $\alpha_{0,05}$ \\
\hline \multicolumn{6}{|c|}{ ASFALT / ASPHALT } \\
\hline $\begin{array}{l}\text { Između grupa / } \\
\text { Between groups }\end{array}$ & 1,402 & 1 & 1,402 & 2,082 & 0,223 \\
\hline $\begin{array}{l}\text { Unutar grupa / } \\
\text { Within groups }\end{array}$ & 2,693 & 4 & 0,673 & & \\
\hline Ukupno / Total & 4,095 & 5 & & & \\
\hline \multicolumn{6}{|c|}{ MAKADAM / MACADAM } \\
\hline $\begin{array}{l}\text { Između grupa / } \\
\text { Between groups }\end{array}$ & 1,042 & 1 & 1,042 & 0,816 & 0,417 \\
\hline $\begin{array}{l}\text { Unutar grupa / } \\
\text { Within groups }\end{array}$ & 5,107 & 4 & 1,277 & & \\
\hline Ukupno / Total & 6,148 & 5 & & & \\
\hline \multicolumn{6}{|c|}{ TRAVA / GRASS } \\
\hline $\begin{array}{l}\text { Između grupa / } \\
\text { Between groups }\end{array}$ & 15,360 & 1 & 15,360 & 16,605 & 0,015 \\
\hline $\begin{array}{l}\text { Unutar grupa / } \\
\text { Within groups }\end{array}$ & 3,700 & 4 & 0,925 & & \\
\hline Ukupno / Total & 19,060 & 5 & & & \\
\hline
\end{tabular}

Standardna pogreška je veća prilikom mjerenja na svim agrotehničkim podlogama 2015. godine (1.) u odnosu na 2016. godinu (2) (tablica 3.). 
Tablica 3. Deskriptivna statistika srednjih vrijednosti s lijeve strane pri gibanju na različitim podlogama (2015. i 2016. godina)

Table 3 Descriptive statistics of the mean values of the left side when moving on different surfaces (2015 and 2016)

\begin{tabular}{|c|c|c|c|c|c|c|c|c|c|}
\hline \multirow[t]{2}{*}{ Grupa } & \multirow[t]{2}{*}{$\mathrm{N}$} & \multirow{2}{*}{$\begin{array}{c}\bar{x} \\
\mathrm{LA}_{\text {eq }}, \mathrm{dB} \\
\text { Mean } L A_{e q}\end{array}$} & \multirow[t]{2}{*}{$\sigma$} & \multirow{2}{*}{$\begin{array}{l}\mathrm{K} . \mathrm{V} . \\
\% \\
\text { C. } V .\end{array}$} & \multirow{2}{*}{$\begin{array}{l}\text { Std. } \\
\text { Pogreška } \\
\text { Std. } \\
\text { Error }\end{array}$} & \multicolumn{2}{|c|}{$\begin{array}{l}\text { 95\% Interval pouzdanosti } \\
\text { za srednju vrijednost } \\
\text { 95\% Confidence Interval } \\
\text { for Mean }\end{array}$} & \multirow[t]{2}{*}{ Min } & \multirow[t]{2}{*}{ Max } \\
\hline & & & & & & $\begin{array}{l}\text { Niža granica } \\
\text { Lower bound }\end{array}$ & $\begin{array}{l}\text { Niža granica } \\
\text { Lower bound }\end{array}$ & & \\
\hline \multicolumn{10}{|c|}{ ASFALT / ASPHALT } \\
\hline 1 & 3 & 74,56 & 0,92 & 1,2461 & 0,5364 & 72,259 & 76,875 & 73,8 & 75,6 \\
\hline 2 & 3 & 71,36 & 0,66 & 0,9329 & 0,3844 & 69,713 & 73,021 & 70,8 & 72,1 \\
\hline Total & 6 & 72,96 & 1,89 & 2,5984 & 0,7740 & 70,977 & 74,956 & 70,8 & 75,6 \\
\hline \multicolumn{10}{|c|}{ MAKADAM / MACADAM } \\
\hline 1 & 3 & 69,53 & 1,16 & 1,6792 & 0,6741 & 66,633 & 72,434 & 68,5 & 70,8 \\
\hline 2 & 3 & 74,56 & 0,75 & 1,0066 & 0,4333 & 72,702 & 76,431 & 73,8 & 75,3 \\
\hline Total & 6 & 72,05 & 2,89 & 4,0157 & 1,1812 & 69,014 & 75,086 & 68,5 & 75,3 \\
\hline \multicolumn{10}{|c|}{ TRAVA / GRASS } \\
\hline 1 & 3 & 68,60 & 0,98 & 1,4357 & 0,5686 & 66,153 & 71,047 & 67,5 & 69,4 \\
\hline 2 & 3 & 73,20 & 0,75 & 1,0314 & 0,4359 & 71,325 & 75,075 & 72,5 & 74,0 \\
\hline Total & 6 & 70,90 & 2,63 & 3,7220 & 1,0773 & 68,131 & 73,669 & 67,5 & 74,0 \\
\hline
\end{tabular}

Analizom varijance među promatranim traktorima utvrđena je statistički značajna razlika u iznosu srednjih vrijednosti izmjerene buke 2015. i 2016. godine pri gibanju traktora po svim agrotehničkim podlogama (tablica 4.). 
Ž. Barač i sur.: Utjecaj različitih vrsta podloga i radnih sati traktora na proizvedenu razinu buke

Tablica 4. Analiza varijance (ANOVA) s lijeve strane pri gibanju na različitim podlogama (2015. i 2016. godina)

Table 4. Analysis of variance (ANOVA) of the left side when moving on different surfaces (2015 and 2016)

\begin{tabular}{|c|c|c|c|c|c|}
\hline & $\begin{array}{l}\text { Suma kvadrata } \\
\text { Sum of Squares }\end{array}$ & df & $\begin{array}{l}\text { Srednja vr. Kvadrata } \\
\text { Mean Square }\end{array}$ & $\mathrm{F}$ & Sig. $\alpha_{0,05}$ \\
\hline \multicolumn{6}{|c|}{ ASFALT / ASPHALT } \\
\hline $\begin{array}{l}\text { Između grupa / } \\
\text { Between groups }\end{array}$ & 15,360 & 1 & 15,360 & 23,510 & 0,008 \\
\hline $\begin{array}{l}\text { Unutar grupa / } \\
\text { Within groups }\end{array}$ & 2,613 & 4 & 0,653 & & \\
\hline Ukupno / Total & 17,973 & 5 & & & \\
\hline \multicolumn{6}{|c|}{ MAKADAM / MACADAM } \\
\hline $\begin{array}{l}\text { Između grupa / } \\
\text { Between groups }\end{array}$ & 38,002 & 1 & 38,002 & 39,448 & 0,003 \\
\hline $\begin{array}{l}\text { Unutar grupa / } \\
\text { Within groups }\end{array}$ & 3,853 & 4 & 0,963 & & \\
\hline Ukupno / Total & 41,855 & 5 & & & \\
\hline \multicolumn{6}{|c|}{ TRAVA / GRASS } \\
\hline $\begin{array}{l}\text { Između grupa / } \\
\text { Between groups }\end{array}$ & 31,740 & 1 & 31,740 & 41,221 & 0,030 \\
\hline $\begin{array}{l}\text { Unutar grupa / } \\
\text { Within groups }\end{array}$ & 3,080 & 4 & 0,770 & & \\
\hline Ukupno / Total & 34,820 & 5 & & & \\
\hline
\end{tabular}

\section{ZAKLJUČCI}

Na temelju obavljenog istraživanja mogu se donijeti sljedeći zaključci:

- izmjerena razina buke je viša 2016. godine pri gibanju traktora po makadamu i travi, što je u skladu s postavljenom hipotezom;

- pri gibanju traktora po asfaltnoj podlozi izmjerena razina buke viša je 2015. godine, što je u suprotnosti s postavljenom hipotezom;

- srednja vrijednost razine buke s desne strane viša je 2016. godine na asfaltu i travi, dok je na makadamskoj podlozi izmjerena srednja razina buke viša 2015. godine; 
Ž. Barač i sur.: Utjecaj različitih vrsta podloga i radnih sati traktora na proizvedenu razinu buke

- srednja razina buke s lijeve strane traktora viša je 2016. godine na makadamu i travi, što je u skladu s postavljenom hipotezom, dok je 2015. godine izmjerena viša razina buke s lijeve strane traktora pri gibanju po asfaltnoj podlozi, što je suprotno postavljenoj hipotezi istraživanja;

- izmjerena razina buke ne prelazi dopuštenu granicu od $90 \mathrm{~dB}$ te ona nije negativno utjecala na zdravlje i koncentraciju rukovatelja pri obavljanju posla.

\section{LITERATURA}

1. Barač, Ž., Plaščak, I., Jurić, T., Jurišić, M., Zimmer, D. (2015.): Starost traktora kao čimbenik proizvedene razine buke, Agronomski glasnik 76 (3): $151-161$.

2. Barač, Ž., Plaščak, I., Jurić, T., Jurišić, M., Zimmer, D., Čuković. I. (2016.): Utjecaj različitih agrotehničkih podloga na generiranje buke pri eksploataciji poljoprivrednog traktora. Proceedings \& abstract of the 9th International Scientific/Professional Conference Agriculture in Nature and Environment Protection, Vukovar 2016., 78 - 81.

3. Celen, I. H. i Ann, S. (2003.): Noise levels of agricultural tractors, Pakistan Journal of Biological Sciences 6 (19): 1706-1711.

4. Fabijanić, K. (2010.): Zaštita zdravlja i sigurnost članova poljoprivrednih kućanstava, Sigurnost 52 (4): 367-379.

5. Goglia, V., Đukić, I., Gospodarić, Z., Filipović, D. (2007.): Neke ergonomske značajke kabine traktora IMT $549 \mathrm{Dv}, 35$. međunarodni simpozij iz područja poljoprivredne mehanizacije, Opatija 2007., $381-391$.

6. Goglia, V., Gospodarić, Z., Beljo - Lučić, R., Đukić, I. (2005.): Neke ergonomske značajke kabine traktora JOHN DEERE 8520, 33. međunarodni simpozij iz područja poljoprivredne mehanizacije, Opatija 2005., 99 -110.

7. Monazzan, M. R., Nadri, F., Khanjani, N., Barsam, T., Shamsi, M., Akbari, H. (2012.): Tractor drivers and bystanders noise exposure in different engine speeds and gears, Iranian Journal of Millitary Medicine 2 (14): 149-154.

8. Savin, L., Nikolić, R., Simikić, M., Furman, T., Tomić, M. (2006.): Rezultati ispitivanja traktora FENDT 930, Časopis Traktori i Pogonske mašine 11: 118-124.

9. Savin, L., Tomić, M., Simikić, M., Mago, L. (2011.): Ispitivanje mogućnosti homologacije traktora YTO 454, Časopis Traktori i pogonske mašine 16 (2): $37-42$. 
Ž. Barač i sur.: Utjecaj različitih vrsta podloga i radnih sati traktora na proizvedenu razinu buke

10. URL 1: Akustika: Home page address: http://www.enciklopedija.hr/natuknica.aspx?id=1265 (2016-9-8)

11. URL 2: Akustični signali: Home page address: https://element.hr/artikli/file/1605 (2016-9-8)

12. URL 3: Buka i zdravlje: Home page address: http://www.zzjzpgz.hr/nzl/68/buka.htm (2016-9-10)

13. URL 4: Postupak slušanja: Home page address: http://www.neuroth.hr/slusna-pomagala/o-sluhu/postupak-slusanja/ (2016-9-7)

14. URL 5: Profesionalne bolesti. Home page address: http://www.hzzo.hr/zastita-zdravlja-na-radu/profesionalna-bolest/ (2017-11-7)

15. ***(2000): Akustika - mjerenje buke strojeva za zemljane radove na mjestu rukovatelja - ispitivanje u uvjetima simuliranoga radnog ciklusa, HRN ISO 6396, Zagreb.

16. ***(2000): Akustika - traktori i strojevi za poljoprivredu i šumarstvo mjerenje buke na mjestu rukovatelja - pregledna metoda, HRN ISO 5131, Zagreb.

17. ***(2010.): Pravilnik o postupku homologacije traktora za poljoprivredu i šumarstvo s obzirom na razinu buke koju osjeća vozač traktora TPV 309 (izdanje 02), NN (79/10), Zagreb.

Adresa autora - Author's address:

Željko Barač, mag. ing. agr., e-mail: zbarac@pfos.hr, doc. dr. sc. Ivan Plaščak, prof. dr. sc. Mladen Jurišić,

Domagoj Zimmer, mag. ing. agr.,

Poljoprivredni fakultet Osijek,

Sveučilište J. J. Strossmayera, Vladimira Preloga 1, 31000 Osijek, Hrvatska
Primljeno-received:

23.06.2017. 
Ž. Barač i sur.: Utjecaj različitih vrsta podloga i radnih sati traktora na proizvedenu razinu buke 